\title{
Halı Yıkama Atıksularının İleri Oksidasyon Prosesi İle Arıtımı
}

\author{
Hüseyin CÜCE* , Şennur Merve YAKUT, Esra ÖZAK \\ Nevşehir Hacı Bektaş Veli Üniversitesi, Mühendislik Mimarlk Fakültesi, Çevre Mühendisliği Bölümü, Nevşehir
}

\begin{abstract}
$\ddot{O} \mathbf{z}$
$\mathrm{Bu}$ çalışmada bir halı yıkama firmasından elde edilen atıksuyun klasik Fenton prosesi ile artımı üzerine çalışılmıştır. Araştırmanın genel amacı, halı yıkama atıksularında bulunan kalıntı organik kirleticilerin giderilmesi için ileri oksidasyon tekniğinin uygulanabilirliğinin değerlendirilmesidir. Fenton prosesi için gerçekleşen deneysel aşamalarda, $\mathrm{pH}$, hidrojen peroksit $\left(\mathrm{H}_{2} \mathrm{O}_{2}\right)$, demir sülfat $\left(\mathrm{FeSO} \cdot 7 \mathrm{H}_{2} \mathrm{O}\right)$ ve kinetik çalışmalar gerçekleştirilmişsir. Fenton prosesinin temel parametrelerinden olan demir ve hidrojen peroksit $\left(\mathrm{H}_{2} \mathrm{O}_{2}\right)$ konsantrasyonları için $(\mathrm{pH}=3$ değerinde) optimizasyon gerçekleştirildikten sonra sonuçların doğruluğunu kanıtlamak amaçlı kinetik çalışma da gerçekleştirilmiştir. İzleyici parametre olarak kimyasal oksijen ihtiyacı (KOI) seçilmiş olup, $7 / 1 \mathrm{H}_{2} \mathrm{O}_{2} / \mathrm{Fe}^{+2}$ oranına sahip oksidasyon prosesi ile elde ettiğimiz verilere göre KOİ giderim verimi $\% 80$ olarak hesaplanmıştır.
\end{abstract}

Anahtar kelimeler: Halı Yıkama Atıksuyu, Fenton Prosesi, KOİ giderimi, İleri Arıtma, Nevşehir.

\section{Treatment of Carpet Washing Wastewater with An Advanced Oxidation Process}

\begin{abstract}
In this study, the wastewater obtained from a carpet washing company was studied on a treatment process with the classic Fenton process. The general aim of this research was based on evaluation of the possibility of applying an advanced oxidation technique for removal of the residuals organic pollutants present in carpet washing wastewater. The $\mathrm{pH}$, hydrogen peroxide $\left(\mathrm{H}_{2} \mathrm{O}_{2}\right)$, iron sulphate $\left(\mathrm{FeSO}_{4} \cdot 7 \mathrm{H}_{2} \mathrm{O}\right)$ and kinetic studies were performed in the experimental steps for the Fenton process. These parameters are $\mathrm{pH}$, hydrogen peroxide $\left(\mathrm{H}_{2} \mathrm{O}_{2}\right)$ dose, ferrous sulfate $\left(\mathrm{FeSO}_{4} \cdot 7 \mathrm{H}_{2} \mathrm{O}\right)$ dose, and time. Also, a kinetic study was conducted to demonstrate the accuracy of the results after optimization of the iron and hydrogen peroxide $\left(\mathrm{H}_{2} \mathrm{O}_{2}\right)$ concentrations $(\mathrm{pH}=3)$, which is one of the basic parameters of the Fenton process. Chemical oxygen demand (COD) was selected as the monitoring parameter and the oxidation process with optimum rate $\left(7: 1 \mathrm{H}_{2} \mathrm{O}_{2} / \mathrm{Fe}^{2+}\right)$ achieved a $\mathrm{COD}$ removal efficiency was calculated as $80 \%$ according to the obtained results.
\end{abstract}

Keywords: Carpet Wash Wastewater, Fenton Process, COD removal, Advanced Treatment, Nevşehir.

\section{Giriş}

Tekstil endüstrisinin bir parçası olan halı benzeri ürünler özellikle ev, otel ve diğer konaklama alanlarında küçüklü büyüklü ebatlarda kullanılmakta, sanayi ölçeğinde giderek artan üretim hızıyla yer almaktadır. Bu halıların bu kadar yaygın kullanılması beraberinde temizleme sorununu getirmektedir. Ev ve işyerleri sınırları içerisinde halı yıkama geleneği zamanla yerini temizleme işini daha teknik usullerle yapmaya çalışan, kısmen kendine yeni sektör açan ve sayıları gittikçe artan halı yıkama tesislerine bırakmıştır. Ev ve otel gibi konaklama noktalarından aldıkları halı vb. tekstil ürünlerini temizleyen halı yıkama firmaları her gün birçok farklı teknik ve kapasitede yıkama işlemi gerçekleştirmekte ve sonuç olarak sentetik ve/veya organik kimyasallar, boya ve deterjan kalıntıları gibi kısmen tehlikeli olabilecek maddeler içeren atıksular ortaya çıkarmaktadır. Alıcı su ortamlarında ekolojik dengeyi bozmalarının yanı sıra çözünmüş oksijen seviyelerinin de hızla düşmesine katkıda bulunan bu tür suların gerçek endüstriyel atıksularla kıyaslandığında nispeten düşük kimyasal oksijen

"Sorumlu yazar: huseyincuce@nevsehir.edu.tr

Geliş Tarihi:29.05.2018, Kabul Tarihi: 10.12.2018 
ihtiyacı (KOİ) içermesinden dolayı arıtımı ve ardından yeniden kullanılabilmesi ya da arıtılıp alt yapı şebeke sistemine dahil edilmesi işletmenin ve kentsel arıtma tesislerinin yükünü azaltacaktır.

Endüstriyel nitelikte atıksuların arıtılması için en uygun teknoloji arayışı devam etmekte ve ileri oksidasyon prosesleri sıklıkla bu sular için tercih edilmektedir [1]. Organik kirleticilerin ayrıştırılması, biyo-parçalanabilirlik oranının yükseltimesi, koku ve renk giderimi için sıklıkla kullanılan ileri oksidasyon proseslerinde reaksiyon sistemleri farklı da olsa aynı kimyasal özellikle karakterize edilirler [2]. Literatürde birçok ileri oksidasyon prosesi uygulamaları (yüksek pH'ta ozonlama, ultraviyole, hidrojen peroksit ve ozon ile kombinasyonlu prosesler, Fenton gibi) mevcuttur. İçlerinden Fenton prosesi sıklıkla kullanılan verimli bir ileri oksidasyon uygulama metodudur. Bu teknikler arasında Fenton prosesi genel tanımıyla, asidik koşullarda $\mathrm{Fe}^{+2}$ ve $\mathrm{H}_{2} \mathrm{O}_{2}$ varlığında meydana gelen bir oksidasyon işlemidir. Fenton oksidasyonunda, $\mathrm{H}_{2} \mathrm{O}_{2}$ 'in $\mathrm{Fe}(\mathrm{II})$ iyonları tarafından katalizlenmesi ve kuvvetli bir oksitleyici olan $\bullet \mathrm{OH}$ radikallerinin oluşması ile dirençli organikler parçalanabilmekte ve atıksuyun BOI/KOİ oranı artarak biyolojik arıtma için daha uygun hale gelmektedir. Fenton prosesi, atık sudaki kirleticilerin oksidasyon yoluyla arıtımının yanında, koagülasyon yoluyla da ikinci bir giderim sağlamaktadır. Fenton oksidasyonu genellikle şu sırayı takip etmektedir [3-6].

$\mathrm{H}_{2} \mathrm{O}_{2}+\mathrm{Fe}^{+2} \rightarrow \mathrm{Fe}^{+3}+\mathrm{HO}^{-}+\mathrm{HO}$.

$\mathrm{HO} \cdot+\mathrm{RH} \rightarrow \mathrm{H}_{2} \mathrm{O}+\mathrm{R}$.

Denklem 1 ve 2'de reaksiyon sonrası oluşan hidroksil radikali kirleticilerin arıtımında rol oynamaktadır. Ardından demir iyonları (katalizör), ferrik hidroksi adı verilen bileşikleri (denklem 3 ve 4) oluştururlar $[7,8]$.

$$
\begin{aligned}
& {\left[\mathrm{Fe}\left(\mathrm{H}_{2} \mathrm{O}\right)_{6}\right]^{+3}+\mathrm{H}_{2} \mathrm{O} \rightarrow\left[\mathrm{Fe}\left(\mathrm{H}_{2} \mathrm{O}\right)_{5}\right]^{+2}+\mathrm{H}_{3} \mathrm{O}^{+}} \\
& {\left[\mathrm{Fe}\left(\mathrm{H}_{2} \mathrm{O}\right)_{5}\right]^{+2}+\mathrm{H}_{2} \mathrm{O} \rightarrow\left[\mathrm{Fe}\left(\mathrm{H}_{2} \mathrm{O}\right)_{4}(\mathrm{OH})_{2}\right]^{+2}+\mathrm{H}_{3} \mathrm{O}^{+}}
\end{aligned}
$$

pH değeri 3 ile 7 arasında iken aşağıdaki denklem (5-7) gerçekleşmektedir [9]. Oluşan radikaller ortamda organik kirletici varsa oksidasyon reaksiyonuna girerek kirleticiyi parçalamakta, ortamda organik madde yoksa mevcut $\mathrm{H}_{2} \mathrm{O}_{2}$ radikalleri bozucu etki göstermektedir[10].

$$
\begin{aligned}
& {\left[\mathrm{Fe}\left(\mathrm{H}_{2} \mathrm{O}\right)_{5} \mathrm{OH}\right]^{+2} \leftrightarrow\left[\mathrm{Fe}\left(\mathrm{H}_{2} \mathrm{O}\right)_{8}(\mathrm{OH})_{2}\right]^{+4}+2 \mathrm{H}_{2} \mathrm{O}} \\
& {\left[\mathrm{Fe}\left(\mathrm{H}_{2} \mathrm{O}\right)_{8}(\mathrm{OH})_{2}\right]^{+4}+\mathrm{H}_{2} \mathrm{O} \leftrightarrow\left[\mathrm{Fe}\left(\mathrm{H}_{2} \mathrm{O}\right)_{7}(\mathrm{OH})_{3}\right]^{+3}+\mathrm{H}_{3} \mathrm{O}^{+}} \\
& {\left[\mathrm{Fe}\left(\mathrm{H}_{2} \mathrm{O}\right)_{7}(\mathrm{OH})_{3}\right]^{+3}+\left[\mathrm{Fe}\left(\mathrm{H}_{2} \mathrm{O}\right)_{5}\right]^{+2} \leftrightarrow\left[\mathrm{Fe}\left(\mathrm{H}_{2} \mathrm{O}\right)_{7}(\mathrm{OH})_{4}\right]^{+5}+2 \mathrm{H} 2 \mathrm{O}}
\end{aligned}
$$

Oksidasyon işleminden sonra $\mathrm{pH}$ nötr değerlere çekilerek demir floklaşması meydana gelmesi sağlanır. Bir süre çökelmeye bırakıldıktan sonra üstte duru faz alt kısımda çamur oluşumu gözlenmektedir.

Atıksuların arıtımı ve beraberinde yeniden kullanımı geçmişten günümüze üzerinde durulan ve dikkatleri üzerine çeken bir konudur. Özellikle az miktarlarda kirletici madde içeren atıksuların arıtılıp tarımsal sulama, kişisel kullanım ve endüstrilerde yıkama suyu olarak kullanımı üzerine çalışmalar yaygınlaşmaktadır. Literatürde son dönemde halı v.b. tekstil ürünlerinin yıkama ve temizlemesini yaparak yüksek oranlarda su tüketimi gerçekleştiren bu tip tesislerin çıkış sularında yapılacak arıtım sonrası arıtılmış suların tesis içi ve çevresinde yeniden kullanılmasına yönelik yeşil mühendislik odaklı düşünceler mevcuttur. Lakin yapılan incelemelerde bu tip atıksuların basit atıksu arıtım tekniklerinden ziyade ileri oksidasyon gibi hızlı bir arıtım yöntemi tercihiyle ilgili bir çalışmaya rastlanılmamıştır. Söz konusu çalışmamız ile hızl, ekonomik ve işletilebilirliği teknik açıdan yüksek olan klasik Fenton arıtımı ile halı yıkama sularının arıtılması, arıtılmış suların tesis içinde yeniden kullanabilirliği noktasında başarı sağlanması ve kentsel arıtma tesisine bu tip tesislerden gelen atıksu yükününün azaltılması hedeflenmiştir. 


\section{Materyal ve Metot}

Bu çalışma ile Nevşehir kent merkezinde yer alan bir halı yıkama tesisinden 2 saatlik kompozit olarak örneklenmiş olan bir atıksu örneği için laboratuvar ortamında Fenton oksidasyonu ile arıtılabilirlik çalışması gerçekleştirilmiştir. Arıtılabilirlik deney setlerinde kullanılan çözeltiler ultra saf su Mp minipure dest up ile hazırlanmış olup, tüm kimyasal tartımları $\pm 0.0001 \mathrm{~g}$ hassaslıkta Bel Engineering (Italy) marka analitik terazi ile gerçekleştirilmiştir. Deneysel aşamada kullanılan kimyasallar analitik saflıkta Merck ve Sigma - Aldrich (Almanya) markalarından temin edilmiştir. Nitrat, fosfat ve sülfat ve renk değerleri için absorbans okumaları UV-VIS spektrofotometre Thermo Scientific Aquamate Plus (USA), ile yapılmış olup KOİ ve sürfaktan analizleri hazır test kitleri HACH Lange LCK (Germany) ile yapılmış son absorbans okumaları için Hach Lange Dr 3900 (Germany) marka spektrofotometre kullanılmıştır. Kit ölçümleri için reaksiyon küvetlerinin gerekli ısıya ulaşılmasında termoreaktör olarak ECO 25 Velp Scientifica (Italy) marka cihaz kullanılmıştır. pH ilk ölçümleri ve arıtım metodu için gereken ayarlama sonras1 okumalar HACH HQ30d (Germany) taşınabilir pH-metre ile gerçekleştirilmiştir. Askıda katı madde (AKM) testleri ve numunelerinin süzülmesi işleminde $0.45 \mu \mathrm{m}$ gözenekli selüloz asetat filtre kağıdı (Sartorius) ve Rocker 600 (Taiwan) marka vakum pompası ile filtrasyon düzeneği kullanılmıştır. Deneysel aşamada kullanılan jar testi Mtops (Korea) düzeneği Şekil 1'de gösterilmektedir.

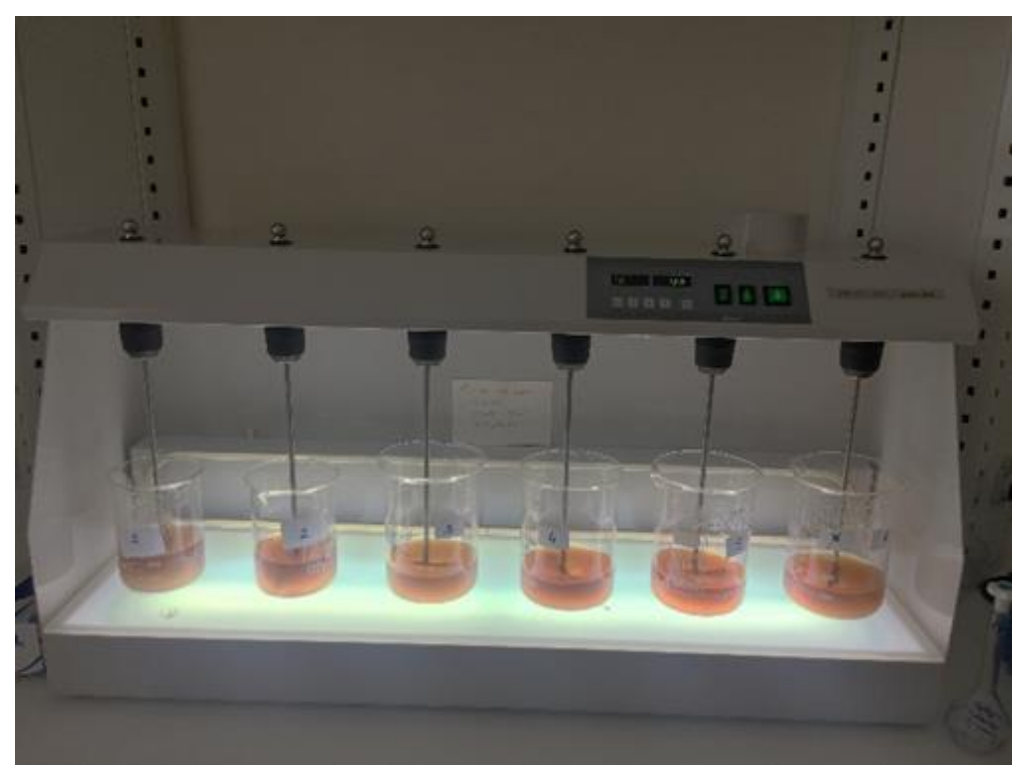

Şekil 1. Fenton prosesi düzeneği

Fenton prosesi deneylerinde $\mathrm{pH}$ optimizasyonu için (Fenton prosesi önceki çalışmalar [11-13] doğrultusunda daha az kimyasal sarfiyatı için en uygun başlangıç $\mathrm{pH}$ değeri 3 olarak seçilmiş ve arıtım sonrası çökelme için $\mathrm{pH}=7$ 'ye ayarlanmıştır), $0.5 \mathrm{~N}, 1 \mathrm{~N}$ ve $6 \mathrm{~N}$ konsantrasyonlarında ayarlanmış $\mathrm{NaOH}$ ve $\mathrm{H}_{2} \mathrm{SO} 4$ çözeltiler kullanılmıştır. Çalışmada ilk aşamada optimum $\mathrm{pH}$ 'da, demir ve hidrojen peroksit dozları eklenildikten sonra ilk 2 dakika hızlı karıştırma (300 dev/dk) sonrasında 45 dakika boyunca yavaş karıştırma (50 dev/dk) ile reaksiyon kaplarında (500 $\mathrm{ml}$ cam beherlerde) işlem sürdürülmüştür. Daha sonra pH nötr aralığa çekilerek (7- 7,5 arasında) flokülasyon için yaklaşık 1 saat çökelmeye bırakılmıştır. Yapılan süzme işlemi sonrasında atıksuyun ilk hali Şekil 2'de gösterilmektedir.

Kinetik çalışmalar için öncelikle 0., 1. ve 2. derece kinetik modelleri kullanılmıştır. Ancak elde edilen $R^{2}$ değerleri düşük olduğundan dolayı başka bir kinetik model kullanılmıştır [14-15]. 


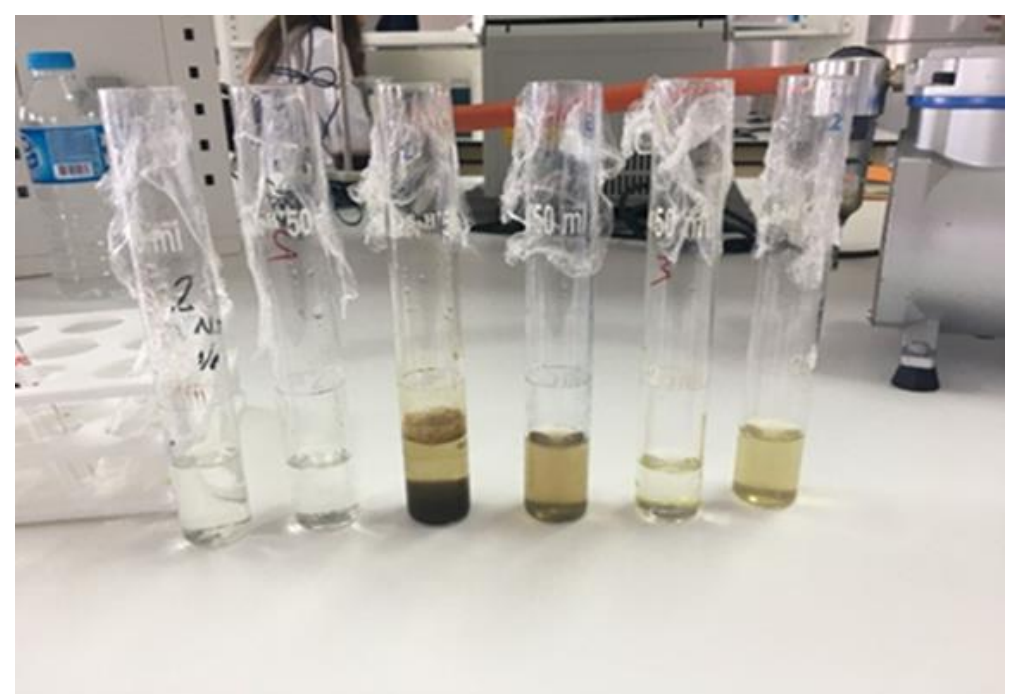

Şekil 2. Arıtılmış atıksuyun analiz yapılmadan önceki bir görünümü

\subsection{Atıksuyun Karakteristiği}

Atıksuda arıtılabilirlik çalışmalarına başlanılmadan önce halı yıkama atıksuyunun karakteristik çalışmaları gerçekleştirilmiştir. Nevşehir İl sınırları içerisinde faaliyet gösteren bir halı yıkama ve temizleme tesisi çıkış sularından 2 saatlik kompozit örnek 5L'lik PE şişelere alınarak $+4{ }^{\circ} \mathrm{C}$ saklama kutusunda laboratuvar ortamına getirilmiş ve karakterizasyon belirleme amaciyla atıksuda; $\mathrm{pH}$, sıcaklık, redoks, iletkenlik, fosfat, sülfat, askıda katı madde, uçucu askıda katı madde (UAKM), KOİ, sürfaktan ve renklilik katsayısı (RES) değerleri tespit edilmiştir. Atıksu karakteristiğinin belirlenmesine yönelik tüm analizler uluslararası standart metodlara [16] uygun olarak gerçekleştirilmiştir. Bu değerleri ihtiva eden değerler Tablo 1'de gösterilmektedir. Analizler kontrol amaçlı tekrarlı olarak gerçekleştirilmiş̧tir.

Tablo 1. Atıksuyun Karakteristiği

\begin{tabular}{lc}
\hline PARAMETRE & ÖLÇÜM DEĞERI \\
\hline $\mathrm{pH}$ & 6,24 \\
Sicaklık, ${ }^{\circ} \mathrm{C}$ & 18,9 \\
Redoks Potansiyeli, mV & 22,3 \\
İletkenlik, $\mu \mathrm{s} / \mathrm{cm}$ & 1288 \\
Sülfat, $\mathrm{mg} / \mathrm{L}$ & 131,7 \\
Fosfat, mg/L & 3,61 \\
AKM, g/L & 218 \\
UAKM, g/L & 1,87 \\
KOİ, mg/L & 1991,04 \\
Sürfaktan, mg/L & 5,13 \\
RES (Renklilik sayısı) & 75,5 \\
\hline
\end{tabular}

\subsection{Demir konsantrasyonunun etkisi}

Deneysel ilk çalışmalarda, optimum pH değerinde $(\mathrm{pH}=3)$ en yüksek KOİ giderim verimini bulabilmek için 50-1600 mg/L arasında değişen değerlerde demir konsantrasyonu denemeleri gerçekleştirilmiştir. $\mathrm{Fe}^{+2}, \mathrm{H}_{2} \mathrm{O}_{2}$ 'nin bileşenlerine ayrışması için bir katalizör görevi görmektedir. Bu yüzden, ferro demir $\left(\mathrm{Fe}^{+2}\right)$ konsantrasyonu arttıkça daha fazla hidroksil radikali ortaya çıkar. Ancak, aşırı demir ilavesi verimi olumsuz etkilemekte ve belirli bir noktadan sonra ortamdaki fazla demir negatif bir etki ortaya çıkarmaktadır [17]. 


\section{3. $\left[\mathrm{Fe}^{+2}\right] /\left[\mathrm{H}_{2} \mathrm{O}_{2}\right]$ etkisi}

Organik madde bulunmayan ortamda gerçekleşen Fenton reaksiyonunda, $\left[\mathrm{Fe}^{+2}\right] /\left[\mathrm{H}_{2} \mathrm{O}_{2}\right]$ oranı 2'ye yaklaştı̆̆ında radikal zincir reaksiyonları hızla sona ermektedir. Burada Fenton reaksiyonunu etkileyen asıl parametre demir konsantrasyonudur. Çünkü hidroksil radikaliyle demir iyonunun tepkimesi, hidroksil radikaliyle hidrojen peroksit arasında geçen tepkimeden 10 kat daha hizlı gerçekleşmektedir [18]. Bu bölümde, $\left[\mathrm{Fe}^{+2}\right] /\left[\mathrm{H}_{2} \mathrm{O}_{2}\right]$ oranı 1:1 ile 1:7 arasında değişen değerlerde, optimum konsantrasyon belirleme uygulamaları yapılmıştır.

\subsection{Kinetik çalışma}

Belirlenen optimum konsantrasyonlara göre, deneysel doğruluğu kanıtlamak amaçlı bir dizi kinetik çalışma gerçekleştirilmiştir. Bu kapsamda araştırma bulgularına en uygun kinetik model belirleme çalışmaları yürütülmüştür. Bu kinetik değerlendirmeler Bölüm 3.3.'te detaylı olarak anlatılmaktadır.

\section{Bulgular ve Tartışma}

\subsection{Demir konsantrasyonunun etkisi}

Yapılan deneysel çalışmalar sonucunda optimum demir konsantrasyonu $100 \mathrm{mg} / \mathrm{L}$ olarak belirlenmiştir. Farklı demir konsantrasyonlarında (100-500 mg/L) gerçekleştirşlen deney sonuçlarına ait verim grafiği Şekil 3'te gösterilmektedir.

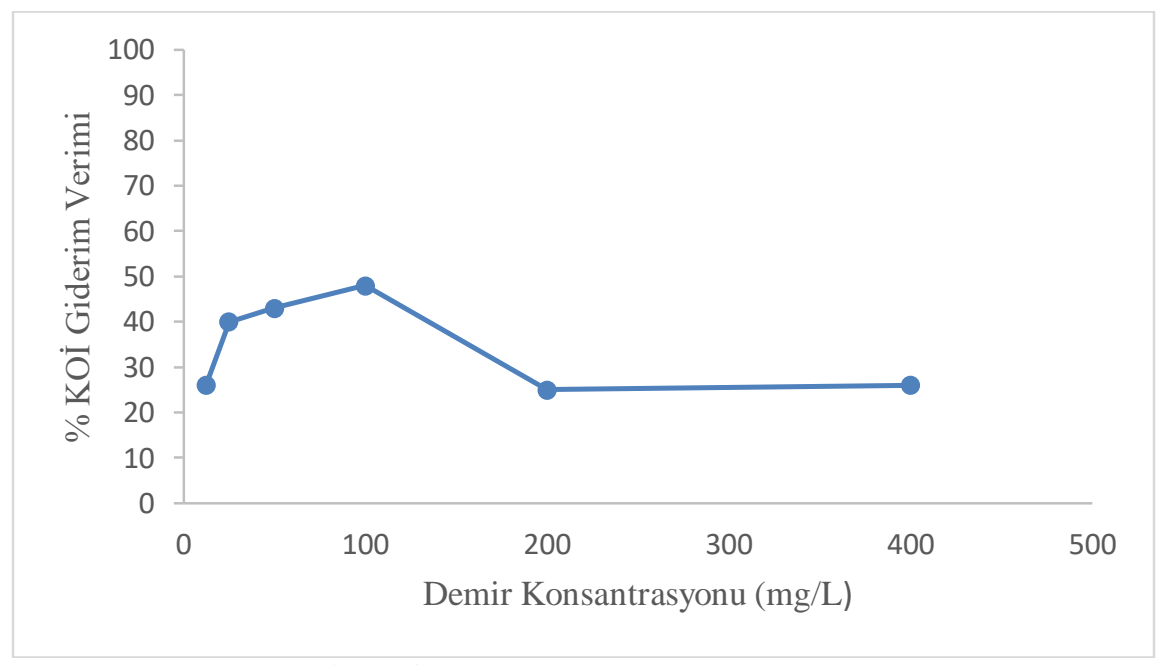

Şekil 3. Demir konsantrasyonu etkisi

$\mathrm{Bu}$ sonuçlara göre artan konsantrasyonlarda sisteme toz halinde eklenen demir bir süre sonra verimi düşürmeye başlamıştır. Bunun nedeni ortamda bulunan fazla demirin bir süre sonra Denklem 8'de görüldüğü gibi hidroksil radikalleriyle tepkimeye girip süpürücü etki oluşturmasından kaynaklanmaktadır $[19,20]$.

$\mathrm{F}_{\mathrm{e}}^{+2}+\mathrm{OH}^{-} \rightarrow \mathrm{F}_{\mathrm{e}}^{+3}+\mathrm{OH}^{-}$

\section{6. $\left[\mathrm{Fe}^{+2}\right] /\left[\mathrm{H}_{2} \mathrm{O}_{2}\right]$ etkisi}

Fenton reaksiyonu esas olarak iki kademeden oluşmaktadır. İlk kademede hidroksil radikalleri oluşmakta ve genellikle daha büyük miktarda kirletici giderimi gerçekleşmektedir. Aynı zamanda bu kademe hızlı bir şekilde meydana gelmektedir. Bu kademeden daha yavaş gerçekleşen ikinci kademede, Fenton reaktifleri azalmakta ve kirletici giderim hızı yavaşlamaktadır Fenton reaksiyonunu etkileyen en önemli parametrelerden biri de demir ve hidrojen peroksit arasındaki orandır [21]. Literatürde bazı 
çalışmalar [22-25], bu oranın belli bir değere kadar artmasıyla birlikte kirletici veriminin de arttığını göstermektedir. Çalışmamızda ilk olarak optimum demir konsantrasyonunu $100 \mathrm{mg} / \mathrm{L}$ seçilmiş (Şekil 4), demir/ hidrojen peroksit oranı $1 / 5,1 / 6$ ve 1/7 olarak belirlenmiştir. Daha sonra demir konsantrasyonunu $50 \mathrm{mg} / \mathrm{L}$ 'ye düşürerek aynı oranlarda denemeler (Şekil 5) gerçekleştirilmiştir.

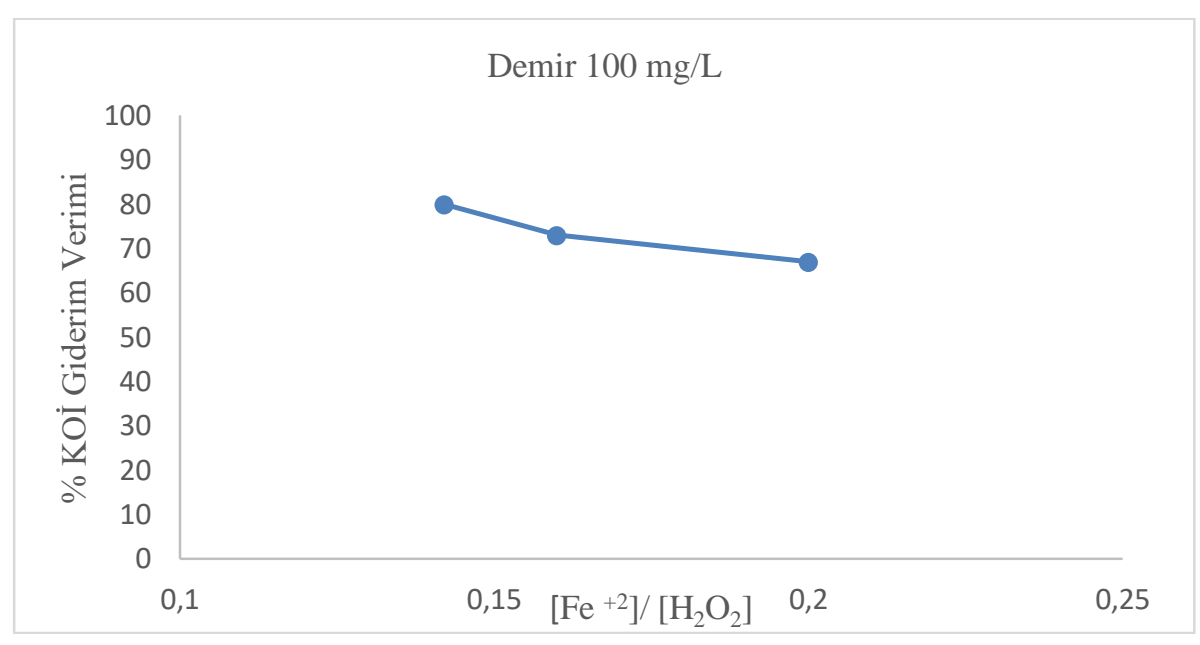

Şekil 4. $\left[\mathrm{Fe}^{+2}\right] /\left[\mathrm{H}_{2} \mathrm{O}_{2}\right]$ oranının etkisi

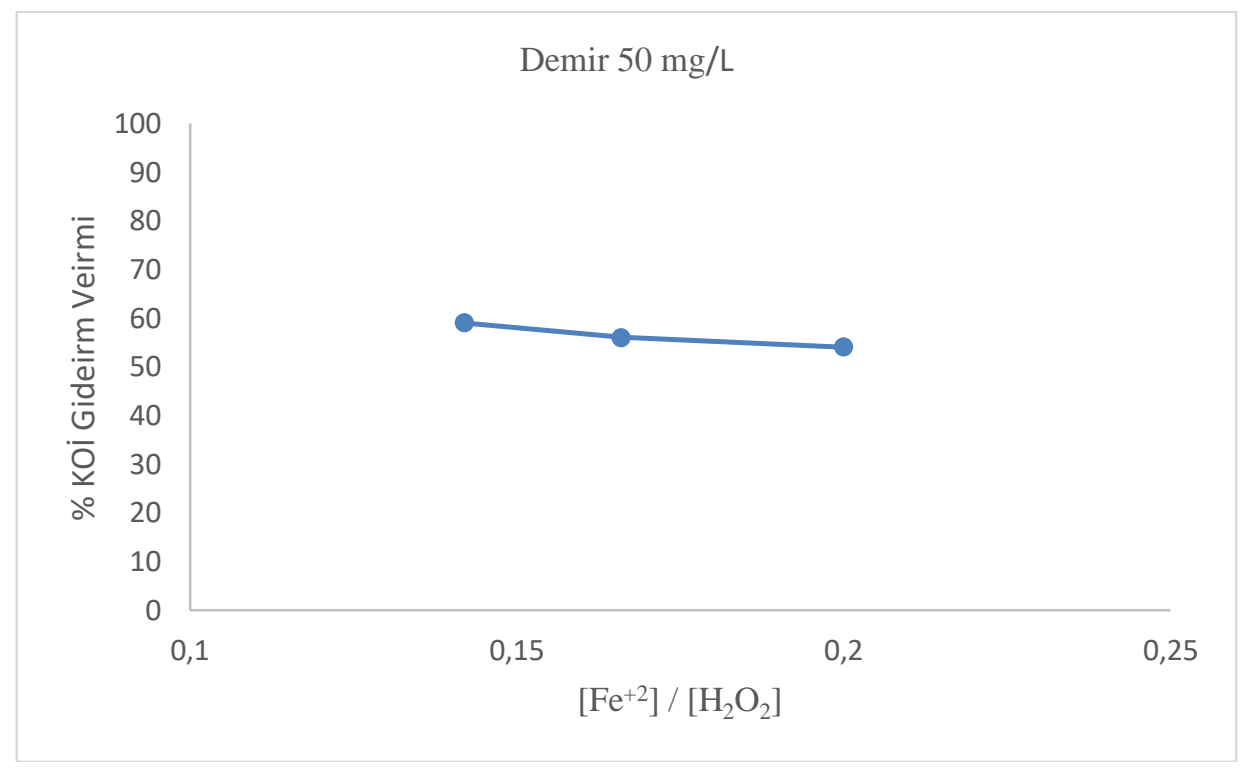

Şekil 5. $\left[\mathrm{Fe}^{+2}\right] /\left[\mathrm{H}_{2} \mathrm{O}_{2}\right]$ oranının etkisi

Elde ettiğimiz sonuçlara göre, en yüksek verim $100 \mathrm{mg} / \mathrm{L} \mathrm{Fe}^{+2}$ konsantrasyonunda ve $\left[\mathrm{Fe}^{+2}\right] /\left[\mathrm{H}_{2} \mathrm{O}_{2}\right]$ oranı $1 / 7$ değerinde $\% 80$ olarak belirlenmiştir. Başlangıç demir konsantrasyonunun hidrojen peroksite göre daha düşük olması durumunda, hidroksil radikalleri, tepkime hızlı olduğu için öncelikle demir katalizörü tepkimeye girmekte olduğundan degredasyon hızının daha yüksek olduğu [22] sonuçlardan da izlenmiştir. 


\subsection{Kinetik Deneyler}

Belirlenen optimum dozlara göre gerçekleştirilen kinetik deney sonuçlarının eğilimi Şekil 6'da gösterilmektedir. Bu kinetik çalışma sonucunda, Fenton prosesinin ilk 5 dakikasında büyük oranda bir giderim sağlandığı görülmektedir. Ancak, oksidasyon oranı, reaksiyonda azalan $\mathrm{H}_{2} \mathrm{O}_{2}$ konsantrasyonları ve ayrıca radikal süpürücü bir etkiye sahip olan katalizör demirin artan konsantrasyonu ile düşüşe geçmiştir.

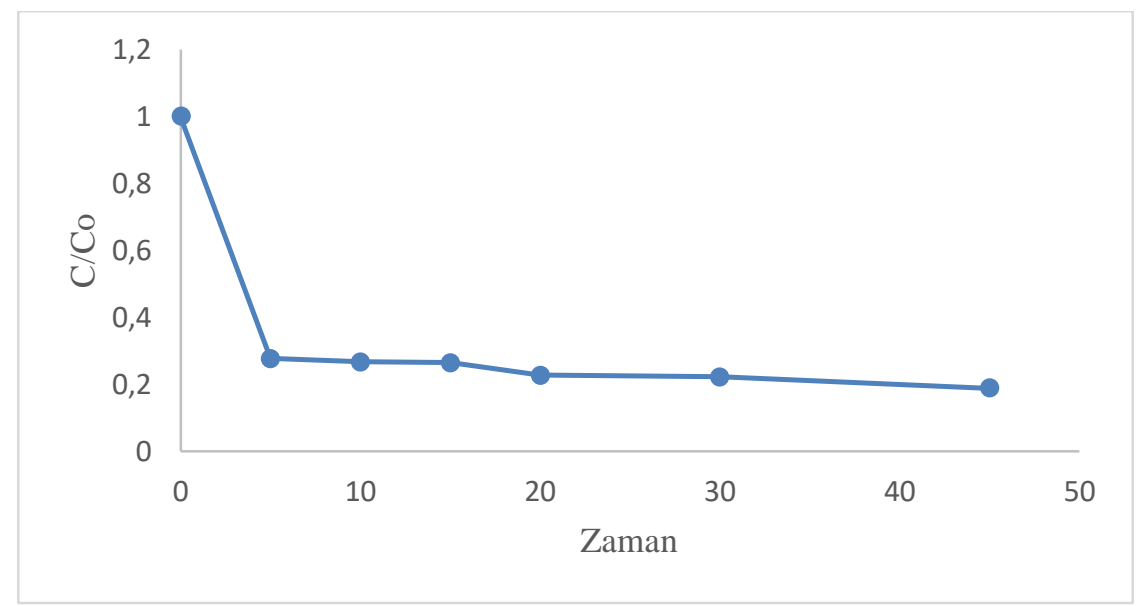

Şekil 6. Fenton işlemi için boyutsuz deney çalışması

Fenton ve fenton benzeri oksidasyon alanında çalışma yürüten birçok araştırmacı atıksulardan çeşitli kirletici ve renk giderimi konularında kinetik analizler yapmışlar [26-28] ve model uygunluk değerlendirmelerinde bulunmuşlardır. Bu araştırma özelinde ise kinetik deneyleri için ilk olarak 0., 1 . ve 2. derece kinetik model çalışmaları yapılmıştır. Bu çalışma sonucu Tablo 2'de görülmektedir.

Tablo 2. 0., 1. ve 2. derece kinetik çalışması

\begin{tabular}{|c|c|c|c|}
\hline $\begin{array}{l}\text { Oksidasyon } \\
\text { Prosesi }\end{array}$ & 0. Derece & 1. Derece & 2. Derece \\
\hline Fenton & 0,9348 & 0,9137 & 0,845 \\
\hline
\end{tabular}

Elde edilen regresyon verileri incelendiğinde en yüksek korelasyonun 0,93 ile 0 . derece kinetiğe uyumlu olduğu ancak bu modellerin hiçbirinde istenilen yüksek korelasyonda verimi yansıtan düzeyde model olmadıkları kanısına varılmıştır. $\mathrm{Bu}$ nedenle bu araştırmadan elde edilen deneysel bulgular üzerinde, fenton kinetiği konusunda farklı araştırmacılar tarafından ortaya atılmış kinetik modellere (örneğin Behnajady ve arkadaşlarının geliştirdiği (2007) [14] BMG matematiksel modeli) göre uygunluk hesaplamaları yapılmıştır. BMG kinetik modeli şu şekilde ifade edilebilir [29]:

$\frac{\mathrm{C}_{\mathrm{t}}}{\mathrm{C}_{0}}=1-\frac{\mathrm{t}}{\mathrm{m}+\mathrm{b}}$

Denklem 9'da verilen b ve m, reaksiyon kinetiği ve oksidasyon kapasiteleriyle ilişkili iki karakteristik sabittir. Burada, sabit $\mathrm{m}$ ve $\mathrm{b}$ değerleri, $1 / \mathrm{m}$ degradasyon oranını temsil eden fiziksel anlamlara sahiptir ve b ifadesi giderim oranı olarak son bozulma durumunun gerekçesi için kullanılır. $\mathrm{m}$ ise maksimum oksidasyon kapasitesini temsil etmektedir. Bu modele göre, $(1 / \mathrm{m})$ değeri ne kadar yüksek ise degredasyon hızı da o kadar yüksek olmaktadır. Ve eğer zaman sonsuz ise, denk. 9 aşağıdaki gibi basitleştirilerek denklem 10 elde edilebilir:

$\frac{C_{t}}{C_{0}}=1-\frac{1}{b}$ 
Yapılan regresyon hesaplamaları karşılaştırıldığında çalışma sonuçlarının BMG modeline uygunluğu tespit edilmiştir. Elde edilen sonuçlar Tablo 3'de gösterilmektedir. Elde edilen verilere göre, korelasyon katsayısı $\mathrm{R}^{2}$ değeri $\left({ }^{0} 0,95\right)$, bu metodun kinetik modele uygun olduğunu ve yüksek oksidasyon sağlandığını göstermektedir.

Tablo 3. Karakteristik sabitler ve katsayılar

\begin{tabular}{llll}
\hline $\begin{array}{l}\text { Oksidasyon } \\
\text { Prosesi }\end{array}$ & $\mathrm{b}$ & $\mathrm{m}$ & $\mathrm{R}^{2}$ \\
\hline Fenton & 9,2311 & 5,5007 & 0,9488 \\
\hline
\end{tabular}

\section{Sonuç ve Öneriler}

Bu çalışma kapsamında bir halı yıkama tesisine ait atıksulardan, klasik Fenton prosesi ile KOİ giderimi üzerine çalış1lmıştır. Fenton prosesinin temel parametrelerinden olan demir konsantrasyonu, demir/hidrojen peroksit oranlarının optimizasyonları ve kinetik çalışmalar örnek bir halı yıkama tesisi atıksuyu için gerçekleştirilmiş ve sonuçlar benzer çalışmalarla kıyaslanmıştır. Özellikle Fenton prosesinin \% 80'i aşan giderim verimi ile kalıntı organik kirletici içeriği yüksek halı v.b. tekstil ürünlerinin yıkama ve temizlenmesi sonrası oluşan atıksular için etkili bir proses olduğu bu çalışma sonuçlarıyla bir kez daha ortaya konulmuştur. Deneysel bulgulara göre, optimum koşullar, $\mathrm{Fe}^{+2}$ konsantrasyonu, $100 \mathrm{mg} / \mathrm{L},\left[\mathrm{Fe}^{+2}\right] /\left[\mathrm{H}_{2} \mathrm{O}_{2}\right]$ oranı, 1/7 olarak tespit edilmiş ve ortalama KOİ giderim verimi \% 80 olarak belirlenmiştir. Bu bağlamda, arıtılmış suların bu derecede kirliliğinden arındırılmış olması halı yıkama tesislerinden çıkış atıksularının tesis içinde yeniden kullanıma uygun olma aşamasında önemli bir adımdır. Ayrıca yüksek arıtım verimi sayesinde alıcı ortama deşarj söz konusu olduğunda düşük bir kirlilik yükü oluşumu gerçekleşecektir. Deneysel verilerin kinetik modele uygunluk incelemesinde ise, literatürde kabul görmüş bir matematiksel modele uygunluğu tespit edilmiş̧ir. Bu araştırma boyunca yürütülen farklı deney koşullarında, söz konusu kinetikler arasında BMG modelinin, Fenton prosesinden alınan eğilimleri en iyi kimyasal model olarak temsil etme avantajına sahip olduğu görülmüştür.

Sonuç olarak, uygulanan klasik Fenton prosesinin halı yıkama atıksularının fiziko-kimyasal arıtımı için uygun olduğu tespit edilmiştir. Halı yıkama atıksularının arıtılmasıyla ilgili olarak literatürde benzer nitelikte bir çalışmaya rastlanılmadığından bu tip atıksular için bu çalışma kapsamında seçilen ileri arıtım yöntemi yerel yönetim ve kuruluşlar için alternatif olarak değerlendirilebilecek bir uygulama olacaktır. Söz konusu halı yıkama tesislerinden çıkacak atıksuların kent arıtma tesislerine kanalizasyon yoluyla doğrudan deşarjına imkan vermeden, ön arıtımı takiben Fenton prosesi gibi hızlı, ekonomik ve sürdürülebilir oksidasyon yöntemleriyle arıtılarak kullanılabilir sulara dönüştürülebilir. Böylelikle hem su kaynaklarının korunması hem de ekonomiye sağlayacağı katkı nedeniyle halı y1kama tesislerinde tüketilen su kadar oluşan atıksu miktarlarının hesaba katılması ve aşırı deterjan kullanımı dolayısıyla çevreye olan olumsuz etkilerinin azaltılabilmesi hususunda gerekli önemin verilmesi gerektiği açıktır. $\mathrm{Bu}$ doğrultuda bu tip tesislerden gelen yüksek organik kalıntı içeren atıksular için ileri oksidasyon tekniklerinin kullanılması noktasında bu çalışmamızın değerli bir araştırma olduğu ve gelecekteki çalışmalara 1şık tutacağı düşünülmektedir.

\section{Kaynaklar}

[1] Mandal T., Maity S., Dasgupta D., Datta S. 2010. Advanced Oxidation Process and Biotreatment: Their Roles in Combined Industrial Wastewater Treatment, Desalination, 250 (1): 87-94.

[2] Sharma S., Ruparelia J.P., Patel M. L. 2011. A General Review on Advanced Oxidation Processes for Wastewater Treatment. International Conference On Current Trends In Technology, Institute Of Technology, Nirma University, Ahmedabad, 382- 481, 08-10 December.

[3] Argun M.E., Karatas M., Dursun S. 2010. Treatment of Mineral-oil Recovery Industry Wastewater by Sequential Aeration and Fenton's Oxidation Process. Environmental Engineering and Management Journal, 9: 643-649.

[4] Badawy M.I., Wahaab R.A., El-Kalliny A.S. 2009. Fenton-biological Treatment Processes for the Removal of Some Pharmaceuticals from Industrial Wastewater. Journal of Hazardous Materials, 167: 567-574. 
[5] Ahn D.H., Chang W.S., Yoon T.I. 1999. Dyestuff Wastewater Treatment Using Chemical Oxidation, Physical Adsorption and Fixed Bed Biofilm Process. Process Biochemistry, 34: 429439.

[6] Argun M.E. 2017. Fenton Oksidasyonu ile İlaç Endüstrisi Atıksuyundan KOİ Gideriminin Kinetik ve Termodinamik Değerlendirmesi, Pamukkale Univ Muh Bilim Derg, 23 (9): 1034-1040.

[7] Üstün G.E., Solmaz Akal S.K., Birgül A. 2007. Regeneration of Industrial District Wastewater Using a Combination of Fenton Process and Ion Exchange-A Case Study. Resources, Conservation and Recycling, 52 (2): 425-440.

[8] Gogate P.R., Pandit A.B. 2004. A Review of Imperative Technologies for Wastewater Treatment. I: Oxidation Technologies at Ambient Conditions. Advances in Environmental Research, 8: 501551.

[9] Gürtekin E., Şekerdağ N. 2008. Bir İleri Oksidasyon Prosesi: Fenton Proses, Pamukkale Üniversitesi Mühendislik Bilimleri Dergisi, 14 (3): 229-236.

[10] Sun Y., Pignatello J.J. 1993. Photochemical Reactions Involved in the Total Mineralization of 2,4D by Fe3+/H2O2/UV. Environmental Science \& Technology, 27: 304-310.

[11] Argun Y.A. 2012. Reaktif Mavi 114 Boyasının Fenton Prosesi ile Giderimi. Yüksek Lisans Tezi, Aksaray Üniversitesi, Aksaray, Türkiye.

[12] Gözükızıl M.F. 2013. Tekstil Endüstrisi Atıksularından Fenton Prosesi ve Biyosorpsiyon Yöntemi İle Renk Giderimi ve Örnek Tesis Modeli. Yüksek Lisans Tezi, Bilecik Şeyh Edebali Üniversitesi, Bilecik, Türkiye.

[13] Iranifam M., Zarei M., Khataee A.R. 2011. Decolorization of C.I. Basic Yellow 28 Solution Using Supported $\mathrm{ZnO}$ Nanoparticles Coupled with Photoelectro-Fenton Process. Journal of Electroanalytical Chemistry, 659 (1): 107-112.

[14] Behnajady M.A., Modirshahla N., Ghanbary F. 2007. A Kinetic Model for the Decolorization of C. I. Acid Yellow 23 by Fenton Process, Journal of Hazardous Materials, 148 (1): 98-102.

[15] Sun S.P., Li C.J., Sun J.H., Shi S.H., Fan M.H., Zhou Q. 2009. Decolorization of an azo dye Orange $G$ in aqueous solution by Fenton oxidation process: Effect of System Parameters and Kinetic Study. Journal of Hazardous Materials, 161: 1052-1057.

[16] APHA., AWWA., WPCF. 2005. Standard Methods for the Examination of Water and Wastewater. American Public Health Association, Washington DC.

[17] Bello M.M., Abdul A.A.R, Anam A. 2018. A Review on Approaches for Addressing the Limitations of Fenton Oxidation for Recalcitrant Wastewater Treatment, Process Safety and Environmental Protection. https://doi.org/10.1016/j.psep.2018.03.034

[18] Neyens E., Baeyens J. 2003. A Review of Classic Fenton's Peroxidation As an Advanced Oxidation Technique, Journal of Hazardous materials, 98 (1-3): 33-50.

[19] Ikehata K., Gamal E.M., 2006. Aqueous Pesticide Degradation by Hydrogen Peroxide/ultraviolet Irradiation and Fentontype Advanced Oxidation Processes: a Review. Journal of Environmental Engineering and Science, 5: 81-135.

[20] Kiril Mert B., Yonar T., Yalili Kilic M., Kestioglu, K. 2010. Pre-treatment Studies on Olive Oil Mill Effluent Using Physicochemical, Fenton and Fenton-like Oxidations Processes, Journal of Hazardous Materials, 174: 122-128.

[21] Solmaz Akal S.K., Azak H., Üstün G.E., Morsünbül T. 2010. Pestisit Gideriminde Fenton Proseslerinin Kullanımına Yönelik Bir Envanter Çalışması, Uludağ Üniversitesi MühendislikMimarlık Fakültesi Dergisi, 15 (1): 179-194.

[22] Demirci C. 2007. Pamuklu Tekstil Endüstrisi Atıksularındaki Rengin Foto-Fenton Prosesiyle Giderimi. Yüksek Lisans Tezi, Fırat Üniversitesi, Elazı̆ğ, Türkiye.

[23] Tezcan H. 2010. Zeytinyağı Atıksularının Fenton Prosesi İle Arıtılması. Yüksek Lisans Tezi, Selçuk Üniversitesi, Konya, Türkiye.

[24] Öden M. K. 2010. Sentetik Tekstil Atıksularında Boyar Maddelerin Fenton Prosesi ile Arıtımı. Yüksek Lisans Tezi, Selçuk Üniversitesi, Konya, Türkiye.

[25] Bayat F. 2013. Zeytin Karasularının Elektrofenton Yöntemi ile Arıtılabilirliğinin İncelenmesi. Yüksek Lisans Tezi, Gebze Yüksek Teknoloji Enstitüsü, Gebze, Türkiye.

[26] Alalm M.G., Tawfik A. Ookawara S. 2015. Degradation of Four Pharmaceuticals by Solar PhotoFenton Process: Kinetics and Costs Estimation. Journal of Environmental Chemical Engineering, 3 (1): 46-55. 
[27] Li X., Shen T., Wang D, Yue X., Liu X., Yang Q., Cao J., Zheng W. Zeng G. 2012. Photodegradation of Amoxicillin by Catalyzed Fe 3+/H2O2 Process. Journal of Environmental Science, 24(2): 269-275.

[28] Ertugay N., Acar F.N. 2017. Removal of COD and Color from Direct Blue 71 Azo dye Wastewater by Fenton's Oxidation: Kinetic Study. Arabian Journal of Chemistry, Vol.10, S.1158-S1163. http://dx.doi.org/10.1016/j.arabjc.2013.02.009

[29] Xu H., Yu T., Wang J., Wu F., Xu A. 2016. Kinetics Study of Fenton Degradation of Acid Yellow G by Online Spectrometry Technology, Nature Env. and Poll. Technology, Vol. 15, No.3: 991-996. 